R O C ZNIKI HUMAN IS T Y C Z N E

Tom LXVIII, zeszyt 5 - 2020

ZESZYT SPECJALNY / SPECIALE UITGAVE

DOI: http://dx.doi.org/10.18290/rh20685sp-6

\author{
PAVLÍNA KNAP-DLOUHÁ \\ \& KATEŘINA KŘÍŽOVÁ
}

\title{
HET BELANG VAN SOCIAAL TOLKEN ALS INSTRUMENT \\ VAN TOLERANTIE IN HET KADER VAN DE HUIDIGE VLUCHTELINGEN- EN ARBEIDSMIGRATIE
}

\begin{abstract}
A b s t r a ct. Naar aanleiding van sociale veranderingen in de West-Europese maatschappij heeft men aan het eind van de 20ste eeuw ingezien dat er een nieuwe kijk nodig was op de tolkwetenschap. Lange tijd werd het sociaal tolken genegeerd ofwel als minderwaardig beschouwd ten voordele van de dominante tolkmodus, het conferentietolken.

De intensivering van de handelscontacten en de arbeidsmigratie binnen de Europese Unie, maar ook de actuele toestroom van vluchtelingen, hebben voor een grote vraag naar tolkendiensten gezorgd op het gebied van sociaal en juridisch tolken. Daarbij is er op de markt maar een beperkt aantal gekwalificeerde tolken ter beschikking en dat vooral in combinaties van minder verspreide talen. Het gebrek aan gekwalificeerde sociaal tolken en vertalers veroorzaakt vertraging in de werking van bepaalde overheidsorganen en sociale diensten, alsook voor de kwaliteit van verleende gezondheidszorg en het maatschappelijk klimaat. De toename van tolk- en vertaalopdrachten, verandering van het professionele profiel van de tolk en vraag naar verlening van taaldiensten in specifieke talencombinaties zijn duidelijke signalen voor kleine talenstudies om hun studenten specialisatie aan te bieden in deze richting. In deze bijdrage worden twee projecten voorgesteld die de kennis over het vak sociaal tolken vergroten. Daarnaast zal de ontwikkeling van modules sociaal tolken besproken worden.
\end{abstract}

Trefwoorden: sociaal tolken; sociaal vertalen; IGA; PACI; tolkwetenschap; meertaligheid; institutionalisering.

Mgr. Pavlína Knap-Dlouhá, Ph.D., en Mgr. Kateřina KŘížová, Ph.D., zijn beiden Odborná Asistentka (Universitair Hoofddocent) bij de Katedra nederlandistiky FF (Vakgroep Neerlandistiek) van de Univerzita Palackého te Olomouc. Knap-Dlouhá is gespecialiseerd in juridisch en zakelijk Nederlands en terminologie, Kř́žžová is taalkundige met als zwaartepunt contrastieve fraseologie. Corresponnetie-adres: Katedra nederlandistiky FF, Univerzita Palackého, Kř́ržkovského 10, 77180 Olomouc, Tsjechië. E-mails: pavlina.knap@upol.cz, ORCID: https://orcid.org/00000002-4262-4132, en katerina.krizova@upol.cz, ORCID: https://orcid.org/0000-0002-7357-9530. 


\section{INLEIDING}

Met het begrip sociaal tolken krijgen we meestal te maken bij tolken binnen een geïnstitutionaliseerde omgeving van een bepaalde maatschappij, waarbij de tolk de communicatie mogelijk maakt tussen enerzijds een vertegenwoordiger van publieke of privé diensten en anderzijds een klant die de taal van het desbetreffende land niet beheerst. Specifiek aan sociaal tolken is het feit dat er in zeer uiteenlopende situaties en omgevingen wordt getolkt. $\mathrm{Er}$ is dus sprake van een grote heterogeniteit aan settings. Bij de meest voorkomende contexten, waarbinnen sociaal tolken worden gebruikt, horen o.a.: ziekenhuizen, artsenpraktijken, politiebureaus, asielzoekerscentra, advocatenkantoren, overheidsdiensten, kindertehuizen, scholen, etc. (De Keyser 0-2).

De basisfunctie van sociaal tolken is het verlenen van toegang tot publieke diensten voor iedereen, onafhankelijk van de taal die de betreffende persoon spreekt (Corsellis 4). Er is derhalve een breed spectrum aan geleverde diensten waar sociaal tolken en de kwaliteit ervan vaak een sleutelrol spelen.

Naar aanleiding van sociale veranderingen in de West-Europese maatschappij heeft men aan het eind van de $20^{\mathrm{e}}$ eeuw ingezien dat er een nieuwe kijk nodig was op de tolkwetenschap (Pöchhacker, "Getting Organized" " 126). Lange tijd werd het sociaal tolken genegeerd ofwel als minderwaardig beschouwd ten voordele van de dominante tolkmodus, het conferentietolken.

Kenmerkend voor sociaal tolken is dat ze communicatie regelen tussen een enkeling die zichzelf representeert (hetgeen onderscheidend is ten opzichte van standaardsituaties, waarbij conferentietolken wordt gebruikt) en een vertegenwoordiger van een organisatie. Meestal hangt sociaal tolken samen met het bemiddelen van basisbehoeftes van een enkeling in de maatschappij en wordt het gebruikt in een bepaalde sociale structuur, waar de communicatiedeelnemers een verschillende positie hebben en tot diverse culturele groepen behoren. Typisch is niet alleen het verschil in de culturele achtergrond, maar ook in de sociale achtergrond. Hierbij kan het zowel gaan om het opleidingsniveau als om de materiële situatie. Het feit dat de vertegenwoordiger of verlener van de publieke dienst vaak ook de vertegenwoordiger is van een staat, bevindt deze zich in de dominante positie, respectievelijk bevoordeelde positie ten opzichte van de communicatiepartner. De klanten van sociaal tolken zijn niet altijd uitsluitend asielzoekers of migranten. De gebruikers van deze diensten kunnen ook toeristen of arbeidsmigranten zijn, die niet afkomstig hoeven te zijn uit derdewereldlanden. 
De intensivering van de handelscontacten en de arbeidsmigratie binnen de Europese Unie, maar ook de actuele toestroom van vluchtelingen, hebben voor een grote vraag naar tolkendiensten gezorgd op het gebied van sociaal en juridisch tolken. Daarbij is er op de markt maar een beperkt aantal gekwalificeerde tolken ter beschikking. Vooral in combinaties van minder verspreide talen, zoals het Tsjechisch en het Nederlands, is dit het geval. Het gebrek aan gekwalificeerde tolken en vertalers veroorzaakt vertraging bij bepaalde overheidsorganen en sociale diensten en heeft directe gevolgen voor de kwaliteit van verleende gezondheidszorg. Dat bemoeilijkt ook de arbeidsvoorwaarden en leefomstandigheden van arbeidsmigranten. De toename van tolk- en vertaalopdrachten, verandering van het professionele profiel van de tolk en vraag naar verlening van taaldiensten in specifieke talencombinaties zijn duidelijke maatschappelijke signalen voor kleine talenstudies om hun studenten de kans te geven voor specialisatie in deze richting. Dit artikel presenteert o.a. twee projecten (Erasmus $+\mathrm{K} 2$ project PACI gericht op strategisch partnerschap in onderwijs ${ }^{1}$ en een intern project van de Vakgroep Nederlands van de Palacký Universiteit IGA 2018²) die de bekendheid van het vak sociaal tolken vergroten.

\section{PROJECT PACI}

Voor migranten is de aanwezigheid van een tolk bij verschillende overheidsinstellingen, bij de politie, in de gezondheidszorg en in de sociale sector essentieel in hun integratieproces. Het gebrek aan gekwalificeerde tolken leidt ertoe dat de communicatie op deze gebieden vaak via een derde taal moet verlopen, waardoor communicatieproblemen en misverstanden ontstaan. Dit kan zowel invloed hebben op het integratieniveau van migranten en de kwaliteit van hun leven, als op de tolerantie van de maatschappij tegenover migranten.

Het project PACI - Professional and Accessible Community Intepreting, a Gateway to Migrant's Integration ${ }^{3}$ is gericht op de opleiding van sociaal tolken in minder verspreide talencombinaties, namelijk Nederlands en Centraal-Europese talen - in het bijzonder Tsjechisch, Slowaaks en Pools. In

\footnotetext{
${ }^{1}$ Voor meer informatie zie "Erasmus+ Programme Guide".

${ }^{2}$ Zie PSUP - Projektový servis Univerzity Palackého v Olomouci, www.psup.cz/igagrantove-projekty/.

${ }^{3}$ Zie PACI - Professional and Accessible Community Intepreting, a Gateway to Migrant's Integrationhttps, www.kgns.info/paci.
} 
Centraal-Europa ontbrak er tot nu toe relevant hoger onderwijs voor sociaal tolken in deze talencombinaties. Dit mondde uit in een samenwerking tussen drie Centraal-Europese neerlandistieken. Het betreft de Comenius Universiteit Bratislava (Slowakije), de Universiteit Wroclaw (Polen) en de Palacký Universiteit Olomouc (Tsjechië). De vierde projectpartner, Vrije Universiteit Brussel (België), werd als voorbeeldland gekozen, waar sociaal tolken inmiddels een stabiel geïnstitutionaliseerde tolkmodus is.

In Vlaanderen is sociaal tolk/vertaler sinds 2007 een officieel erkend beroep. Het beroepsprofiel van sociaal tolk is uitgewerkt in de Federaal Overleg Sociaal Vertalen en tolken (FOSOVET). ${ }^{4}$ Sinds 2009 bestaat er een wettelijk kader voor sociaal tolken/vertalen in het Integratiedecreet dat door het Vlaams Parlement goedgekeurd werd ${ }^{5}$. Tot de grootste centra voor sociaal tolken in Vlaanderen behoren: Agentschap integratie en inburgering ${ }^{6}$ met de zetel in Brussel, het Sociaal Vertaalbureau van Brussel Onthaal vzw, ${ }^{7}$ Atlas, integratie \& inburgering Antwerpen ${ }^{8}$ en IN-Gent vzw.

In Centraal-Europa is het sociaal tolken niet geïnstitutionaliseerd en wordt het vaak met gerechtstolken verward. Toch is er in de laatste vijftien jaar, in het bijzonder in Tsjechië, een duidelijke toename van de belangstelling voor het sociaal tolken en vertalen, vooral bij non-profitorganisaties $^{9}$, maar ook bij overheidsinstellingen ${ }^{10}$ en in de academische wereld ${ }^{11}$.

Het belangrijkste doel van het project PACI is de professionalisering van het sociaal tolken/vertalen in Centraal-Europa. Daarnaast heeft het project de volgende doelstellingen:

1. Vier e-learning cursussen voor een intensieve training van de universiteitsstudenten Nederlands op het gebied van sociaal tolken en vertalen, uitgewerkt door één van de vier projectpartners: Language Technologies in

\footnotetext{
${ }^{4}$ Zie document van de FOSOVET “... beroepsprofiel van sociaal tolk”, docplayer.nl/14140 807-Fosovet-cofetis-vzw-federaal-overleg-voor-het-sociaal-vertalen-en-tolken-beroepsprofiel-vansociaal-tolk.html.

${ }^{5}$ Het Integratiedecreet, goedgekeurd door het Vlaams Parlement op 22 april 2009.

${ }^{6}$ Zie website: www.integratie-inburgering.be/

${ }^{7}$ Zie website: www.sociaalvertaalbureau.be/

${ }^{8}$ Zie website: www.atlas-antwerpen.be/nl/over-atlas/wat-doet-atlas

${ }^{9}$ META o.p.s., Integrační centrum Praha o.p.s., InBáze o. s., Most PRO o. p. s., Klub Hanoi o. s., Slovo 21 z. s.

${ }^{10}$ MŠMT (het Tsjechische Ministerie van Onderwijs), MPSV (het Tsjechische Ministerie van Werkgelegenheid en Sociale Zaken).

${ }^{11}$ ÚTRL FF KU (Translatologisch Instituut van de Karlsuniversiteit Praag), FF UP (Filosofische Faculteit van de Palacký Universiteit Olomouc, vakgroep Anglistiek en Amerikanistiek en Neerlandistiek).
} 
Community Interpreting and Translation (Vrije Universiteit Brussel), Community/Institutional Translation: Context and Techniques (Comenius Universiteit Bratislava), Community Interpreting: Context and Techniques (Palacký Universiteit Olomouc) en Praxeological, Institutional and Ethics Aspects of Community Interpreting and Translation (Universiteit Wroclaw). Deze cursussen zullen (voor ingeschreven studenten) toegankelijk zijn op het leerplatform Moodle op de server van de Comenius Universiteit Bratislava. Alle cursussen volgen het klassieke didactische traject van de theorie naar de praktijk. Omdat ze zowel in de Nederlandstalige versie als in de Engelstalige versie ter beschikking zullen zijn, kunnen ze ook nuttig zijn voor een breder publiek van studenten en docenten sociaal tolken en vertalen. Elke cursus bevat 10 lessen. Er wordt uitgegaan van een studielast van ca. 7 uur per les (3 ECTS/cursus).

2. Meertalige terminologische database (Nederlands, Slowaaks, Tsjechisch, Pools) voor sociaal tolken en vertalers die de hoofddomeinen van het project (medische zorg, onderwijs en schoolwezen, politie en sociale instellingen) zal omsluiten. De elektronische database kan in de toekomst als een sjabloon voor andere talencombinaties gebruikt worden.

3. Syllabus voor de zomerschool sociaal tolken en vertalen die in 2020 in Brussel zal plaatsvinden. De syllabus zal van de voorgestelde e-learning cursussen uitgaan en als een elementaire didactische bron van materialen voor de deelnemers van de zomerschool dienen. De syllabus kan ook als een vademecum en inspiratiebron gezien worden voor potentiële organisatoren van zomercursussen sociaal tolken en vertalen voor andere talencombinaties.

4. Tweetalige monografie (in het Engels en het Slowaaks) over de betekenis, de praktijk, de didactiek en de professionalisering van het sociaal tolken en vertalen in Europese landen. Deze monografie zal de belangrijkste wetenschappelijke output van het project zijn. Uit het onderzoek van de projectleden naar de stand van zaken op het gebied van sociaal tolken in België, Oostenrijk, Spanje en in de landen van Centraal-Europa blijkt dat België de meeste ervaring met sociaal tolken heeft (het land van "best practice") en dus als voorbeeld voor Centraal-Europese landen kan dienen.

\section{IGA-PROJECT 2018}

IGA-projecten zijn grantprojecten van de Palacký Universiteit (Tsjechië) die sinds 10 jaar jaarlijks kunnen worden ingediend door afzonderlijke vak- 
groepen en die specifiek universitair onderzoek bevorderen. Ze worden uitgevoerd door masterstudenten en/of PhD-studenten in samenwerking met academische medewerkers. ${ }^{12}$

Het project van het jaar 2018 van de vakgroep neerlandistiek droeg de naam Sociaal tolken in de Tsjechische Republiek en in de Lage Landen (Komunitní tlumočení v České republice a v nizozemsky hovořících zemích). Dit project is ontstaan, omdat het vak sociaal tolken in Tsjechië, ondanks het maatschappelijke belang en de sociale relevantie ervan wegens de groeiende toestroom van migranten naar Europa, nog steeds niet tot de vakgebieden behoort, waaraan veel wetenschappelijke publicaties of onderzoeksprojecten gewijd zijn.

In de westerse wereld hebben tijdens de laatste decennia veel onderzoe$\operatorname{kers}^{13}$ aandacht besteed aan dit vakgebied binnen de tolkwetenschap. Er bestaan veel hieraan gerelateerde projecten en om het beroep van sociaal tolk uit te voeren moet in het algemeen aan concrete opleidingseisen worden voldaan. Deze eisen bestaan uit een opleiding sociaal tolken (België) of een volledige vakgerichte cursus (Nederland).

De opkomst van sociaal tolken ging gepaard met de sterke toename van het aantal asielzoekers, vooral in de jaren tachtig. Sociaal tolken is in de moderne Nederlandssprekende maatschappij niet weg te denken en heeft in de laatste decennia een vaste structuur en positie opgebouwd. Dit feit en de genoemde diversiteit boden voldoende ruimte voor het uitvoeren van een contrastief onderzoek dat in het kader van het IGA-project tot stand kwam.

Tot de concrete onderzoeksvragen, die in het onderzoek gesteld werden, behoren o.a.: welke trends prevaleren in de evolutie van het sociaal tolken in Tsjechië en in de Lage Landen? Hoe is dit tolkgebied verankerd in de afzonderlijke juridische structuren? Welke levensomstandigheden en mogelijkheden hebben buitenlanders die niet de officiële taal van het land beheersen in Tsjechië en hoe is dit in Nederland/België geregeld? Met welke interculturele problemen en/of verschillen hebben sociaal tolken te kampen? Hoe wordt tegenwoordig de rol van de sociaal tolk gezien? Is deze slechts een bemiddelaar tussen twee talen of behoort hij/zij ook de rol te spelen van de interculturele bemiddelaar met bredere taken en competenties? Wat verstaan we onder het begrip deontologische/ethische code voor sociaal tolken?

\footnotetext{
${ }^{12}$ Deze IGA-projecten duren 1-3 jaar.

${ }^{13}$ O. a. Mikkelson, Wadensjö, Pöchhacker, Phelan, Angelelli, De Keyser, Hale, Hertog en Gentile.
} 
Hoewel sociaal tolken een belangrijke sociale functie vervullen - een gedeelte van de bevolking zou zonder hen geen toegang hebben tot de openbare sector en infrastructuur, vooral tot medische, sociale en juridische diensten - staan hun vak, positie en waardering in veel Centraal-Europese Landen nog lang niet op het niveau van de Lage Landen. Het feit dat sociaal tolken alleen in beperkte mate aan bepaalde universiteiten gestudeerd kan wor$\operatorname{den}^{14}$, hangt nauw samen met het feit dat het vakgebied een eenduidige academische afbakening in de tolkwetenschap mist. Dit heeft tot gevolg dat er op dit gebied onvoldoende wetenschappelijke studies en didactisch materiaal worden ontwikkeld. Het project probeerde op deze gebreken te focussen, want indien men in de toekomst niet meer ruimte zal scheppen voor academisch onderzoek, zal het heel moeilijk worden om de overheid en organisaties te overtuigen van het belang van sociaal tolken.

Het beschreven IGA-project mondde uit in een monografie ${ }^{15}$ over de situatie van sociaal tolken in Tsjechië en in de Lage Landen. De monografie biedt een overzicht van het juridische en organisatiekader van sociaal tolken in Nederland en België (Vlaanderen) en in de Tsjechië. Daarnaast werden het onderzoeksgebied en de grondslagen van sociaal tolken gedefinieerd, evenals de rol van de sociaal tolk in de maatschappij en de rol van de sociaal tolk als intercultureel bemiddelaar. Verder werden de grootste groepen buitenlanders in kaart gebracht die gebruik maken van de diensten van sociaal tolken in Tsjechië en de Lage Landen. Bovendien richtte het project zich op de vergelijking van de structuur en organisatie van het verlenen van diensten van sociaal tolken. Daarnaast wordt er aandacht besteed aan de opleidingsmogelijkheden van sociaal tolken en de gebieden waarin het gebruik van diensten, geleverd door sociaal tolken, het meeste voorkomt en het belangrijkste is.

\section{CONCLUSIE}

Concluderend kan gesteld worden dat sociaal tolken als onderzoeksterrein en studievak in Centraal-Europa nog een lange weg te gaan heeft. Als we de situatie in de Lage Landen vergelijken met de situatie in Tsjechië, vergelij-

\footnotetext{
${ }^{14}$ In Polen zijn dat de Universiteiten in Poznań, Krakau, Gdańsk, Warschau en Wrocław (PACI). De studies variëren van een aantal modules tot postdoc studies. In Tsjechië ÚTRL FF KU, FF UP - vakgroep Anglistiek en Amerikanistiek (bachelorstudie) en Neerlandistiek (PACI). In Slowakije aan de Comenius Universiteit in Bratislava (PACI).

${ }^{15}$ De monografie wordt in 2019 voorbereid om uitgegeven te worden door de Uitgeverij van de Palacký Universiteit Olomouc.
} 
ken we een grootschalige en een kleinschalige markt wat het gebied van sociaal tolken aangaat. Sociaal tolken, met name in België, geniet vandaag de dag al een hoge mate van professionalisering en ook in Nederland maakt dit vakgebied een snelle ontwikkeling door. Dit is geen verrassing, als we beseffen dat volgens het CBS op 1 januari 2018 ongeveer 23,1\% van de Nederlanders een migratieachtergrond had (Butter). Sociaal tolken functioneren dan ook als een van de basisinstrumenten van tolerantie. In de multiculturele meertalige samenleving spelen ze een sleutelrol, waarbij ze de anderstaligen een gevoel van zekerheid en begrip bieden. In Tsjechië is sociaal tolken nog niet geprofessionaliseerd, maar er is wel vooruitgang te zien, bijvoorbeeld in het werk van non-profitorganisaties die niet primair gericht zijn op het aanbieden van (sociaal) tolkdiensten, maar regelmatig activiteiten organiseren, waarbij informatie over sociaal tolken verspreid wordt.

Er werden hier twee onderzoeksprojecten (op nationaal en internationaal niveau) gepresenteerd die een stimulans proberen te zijn bij een betere informatieverspreiding over sociaal tolken, hetgeen noodzakelijk is voor de vooralsnog ontbrekende algemene en juridische erkenning van het beroep van sociaal tolk in Centraal-Europese landen. Verdere aanzetten zullen hopelijk in de toekomst volgen, zodat verdere ontplooiing van sociaal tolken mogelijk is. Hiermee worden o.a. concrete maatregelen op overheidsniveau bedoeld, vooral wat het vaststellen van kwaliteitseisen en opleidingen tot sociaal tolk en vertaler betreft.

\section{BIBLIOGRAFIE}

Anderson, R.W. Bruce. "Perspectives on the Role of Interpreter". The Interpreting Studies Reader, ed. Franz Pöchhacker en Miriam Shlesinger, London, Routledge, 2002, pp. 209217.

Angelelli, Claudia V. "The Interpersonal Role of the Interpreter in Cross-Cultural Communication: A Survey of Conference, Court and Medical Interpreters in the US, Canada and Mexico". The Critical Link 3: Interpreters in the Community, ed. Louise Brunette, Georges L. Bastin, Isabelle Hemlin en Heather Clarke, John Benjamins Publishing Company, 2003, pp. 15-26.

Angelelli, Claudia V. Revisiting the Interpreter's Role. A Study of Conference, Court and Medical Interpreters in Canada, Mexico, and the United States, John Benjamins, 2004.

Bancroft, Marjory. “Community Interpreting: A Profession Rooted in Social Justice.' The Routledge Handbook of Interpreting, ed. Holly Mikkelson en Renée Jourdenais, New York, Routledge, 2015, pp. 217-235.

Butter, Ewoud. 'Nederlanders, buitenlanders, 'allochtonen.' De cijfers.” Republiek allochtonië. http:// www.republiekallochtonie.n1/blog/feiten/nederlanders-buitenlanders-allochtonen-de-cijfers. Geraadpleegd op 27.07.2018. 
Bot, Hanneke. "The Myth of the Uninvolved Interpreter Interpreting in Mental Health and the Development of a Three-Person Psychology". The Critical Link 3: Interpreters in the Community, ed. Louise Brunette, Georges L. Bastin, Isabelle Hemlin en Heather Clarke, John Benjamins Publishing Company, 2003, pp. 27-35.

Chápete, člověče, co vám řikám? aneb Komunitní tlumočení u nás: (Návod, jak se domluvím s uprchlikem, pacientem, neslyšícím...), ed. Amalaine Diabová et al., Praha, Jednota tlumočníků a překladatelů, 2014.

Corsellis, Ann. Public Service Interpreting: The First Steps. Palgrave Macmillan, 2008.

Critical Link International, criticallink.org/what-is-critical-link. Geraadpleegd op 30.09. 2018.

ČSN ISO 13611: Tlumočnické služby - Směrnice pro komunitní tlumočení. Ústav pro technickou normalizaci, metrologii a státní zkušebnictví, Praha, 2015.

De Keyser, Raïssa. Horen, zien en tolken. Werken als tolk in de sociale sector, Gent, Academia Press, 2006.

Doornbos, Nienke. Op verhaal komen: institutionele communicatie in de asielprocedure. Wolf Legal Publishers, 2006.

"Erasmus+ Programme Guide". Europese Commissie, https://ec.europa.eu/programmes/erasmusplus/programme-guide/part-b/three-key-actions/key-action-2/strategic-partnerships-fieldeducation-training-youth_nl?keyword=K2. Geraadpleegd op 27.07.2018.

Favaron, Roberta. Interpreting in a bilingual healthcare facility. Dissertation, University of Vienna, Zentrum für Translationswissenschaft, 2010.

FOSOVET - COFETIS vzw Federaal Overleg voor het Sociaal Vertalen en Tolken. “... beroepsprofiel van sociaal tolk", docplayer.nl/14140807-Fosovet-cofetis-vzw-federaal-overlegvoor-het-sociaal-vertalen-en-tolken-beroepsprofiel-van-sociaal-tolk.html. Geraadpleegd op 27.07.2018.

Figarová, Anita. Sociaal tolken in Vlaanderen en Tsjechië vanaf 2004: een vergelijking. Masterscriptie, Univerzita Palackého v Olomouci, Filozofická fakulta, 2012.

Garber, Nathan. "Community Interpretation: A Personal View". The Critical Link 2: Interpreters in the Community, ed. Silvana E. Carr, Roda P. Roberts, Aideen Dufour en Dini Steyn, John Benjamins, 1997, pp. 9-21.

Gentile, Paola. "Het zelfbeeld van sociaal tolken, een miskend en onderschat beroep: Overzicht van de huidige situatie in Nederland". Internationale Neerlandistiek, vol. 55, nr. 1, 2017, pp. 1-22.

Hale, Sandra Beatriz. Community Interpreting. Palgrave Macmillan, pp. 2007.

Hertog, Erik. "Community interpreting". Handbook of Translation Studies 1, ed. Yves Gambier en Luc van Doorslaer, John Benjamins, 2010, pp. 49-54.

Holkupová, Jiřina. The Role of Community Interpreter from the Point of View of Users' Expectations, Masterscriptie, Praha, Univerzita Karlova, 2010.

Kaufert, Joseph M., en Robert W. Putsch. "Communication through Interpreters in Healtcare: Ethical Dilemmas Arising from Differences in Class, Culture, Language, and Power". The Journal of Clinical Ethics, vol. 8, nr. 1, 1997, pp. 71-87.

Knap-Dlouhá, Pavlína. "De positie van beëdigde tolken en vertalers in Tsjechië en Nederland en een casusonderzoek naar tolken in een interlandelijke adoptieprocedure". Brünner Beiträge zur Germanistik und Nordistik, vol. 29, nr. 2, 2015, pp. 141-149. 
Leanza, Yvan. "Roles of community interpreters in pediatrics as seen by interpreters, physicians and researchers". Interpreting, vol. 7, nr. 2, 2005, pp. 167-193.

Macáková, Dita. Sociaal tolken in Nederland en Tsjechië. Een vergelijking, Masterscriptie, Univerzita Palackého v Olomouci, 2018.

Mikkelson, Holly. "Community interpreting: An emerging profession”. Interpreting, International Journal of Research and Practice in Interpreting, vol. 1, nr. 1, 1996, pp. 125-129.

Nakládalová, Lucie. Komunitni tlumočení v azylových zařizenich České republiky, Masterscriptie, Univerzita Karlova v Praze, 2005.

NN. "170 jobs in gevaar bij Agentschap Integratie en Inburgering”. HLN - Het Laatste Nieuws, www.hln.be/de-krant/170-jobs-in-gevaar-bij-agentschap-integratie-en-inburgering a760656b/. Geraadpleegd op 27.07.2018.

NN. "Hoe het ontslag van 46 personeelsleden Agentschap Inburgering al 3 jaar geleden gepland werd". De Morgen, www.demorgen.be/binnenland/hoe-het-ontslag-van-46personeelsleden-agent schap- inburgering-al-drie-jaar-geleden-gepland-werd-b1c56707/. Geraadpleegd op 27.07.2018.

PACI - Professional and Accessible Community Intepreting, a Gateway to Migrant's Integration, www.kgns.info/paci. Geraadpleegd op 27.07.2018.

Phelan, Mary. The Interpreter's Resource. Multilingual Matters, 2001.

Pöchhacker, Franz. “'Getting Organized': The Evolution of Community Interpreting”. Interpreting, vol. 4, nr. 1, 1999, pp. 125-140.

Pöchhacker, Franz. "The Community Interpreter's Task: Self-Perception and Provider Views". The Critical Link 2: Interpreters in the Community, ed. Silvana E. Carr, Roda P. Roberts, Aideen Dufour en Dini Steyn, John Benjamins, 1997, pp. 49-65.

Pöchhacker, Franz. Introducing Interpreting Studies. London, Routledge, 2004.

Pöchhacker, Franz. "Critical Linking Up: Kinship and Convergence in Interpreting Studies". The Critical Link 4: Professionalisation of interpreting in the community, ed. Cecilia Wadensjö, Birgitta Englund Dimitrova en Anna-Lena Nilsson, John Benjamins, 2007, pp. 11-23.

Pöllabauer, Sonja. 'Interpreting in Asylum Hearings. Issues of Role, Responsibility and Power.' Interpreting, vol. 6, nr. 2, 2004, pp. 143-180.

"Praktisch en effectief. Rapport Commissie kwaliteitseisen tolken en vertalers". Bureau Wbtv www.bureauwbtv.n1/binaries/content/assets/wbtv/onderzoek/rapport-praktisch-eneffectief.pdf. Geraadpleegd op 28.07.2018.

PSUP - Projektový servis Univerzity Palackého v Olomouci, www.psup.cz/iga-grantoveprojekty/. Geraadpleegd op 27.07.2018.

Roberts, Roda. "Community Interpreting: A Profession in Search of Its Identity". Teaching Translation and Interpreting 4: Building bridges, ed. Eva Hung, John Benjamins, 2002, pp. 157-175.

Roy, Cynthia B. Interpreting as a Discourse Process. Oxford University Press, 2000.

Setis. Service de Traduction et Interpretariat Sociale Wallonnie, www.setis.be. Geraadpleegd op 27.07.2018.

"Sociaal tolken en vertalen". Agentschap Integratie en Inburgering, www.agii.be/ thema/sociaaltolken-en-vertalen/sociaal-tolken-en-vertalen/europees-netwerk-voor-sociaal-tolken-envertalen-enpsit\#nederland. Geraadpleegd op 25.08.2018.

Swabey, Laurie, en Paula Gajewski Mickelson. "Role Definition: A Perspective on Forty Years of Professionalism in Sign Language Interpreting". Crossing Borders in Community 
Interpreting. Definitions and dilemmas, ed. Carmen Valero-Garcés en Anne Martin, John Benjamins Publising Company, 2008, pp. 51-80.

Teorie a didaktika tlumočení, ed. Ivana Čeňková et al., Praha, Univerzita Karlova, 2001.

The Critical Link 2: Interpreters in the Community, ed. Silvana E. Carr, Roda P. Roberts, Aideen

Dufour en Dini Steyn (eds.). John Benjamins, 1997. Benjamins Translation Library 19.

Wadensjö, Cecilia. Interpreting as Interaction. Longman, 1998.

\section{ZNACZENIE USTNYCH TŁUMACZEŃ SPRAW SOCJALNYCH JAKO INSTRUMENT TOLERANCJI W KONTEKŚCIE MIGRACJI UCHODŹCÓW I MIGRACJI ZAROBKOWEJ}

$$
\text { Streszczenie }
$$

W wyniku zmian społecznych i cywilizacyjnych Europy Zachodniej pod koniec XX wieku uznano, że potrzebne jest nowe spojrzenie na traduktologię. Przez długi czas ustne thumaczenia spraw socjalnych były ignorowane lub uważane za gorsze na korzyść dominującego wówczas trybu tłumaczenia - tłumaczenia konferencyjnego.

Zintensyfikowanie kontaktów handlowych i migracja zarobkowa w ramach Unii Europejskiej, a także obecny napływ uchodźców doprowadziły do dużego zapotrzebowania na usługi tłumaczeń ustnych spraw socjalnych i prawniczych. Ponadto na rynku dostępna jest tylko ograniczona liczba wykwalifikowanych tłumaczy ustnych, zwłaszcza w kombinacji języków rzadziej używanych. Brak wykwalifikowanych thumaczy ustnych i pisemnych powoduje opóźnienia w funkcjonowaniu niektórych organów rządowych i utrudnia świadczenia socjalne, a także obniża jakość świadczonej opieki zdrowotnej i negatywnie wpływa na klimat społeczny. Wzrost liczby tłumaczeń ustnych i pisemnych, zmiana profilu zawodowego tłumacza ustnego oraz zapotrzebowanie na świadczenie usług językowych w określonych kombinacjach językowych są wyraźnym sygnałem w nauczaniu języków obcych, aby oferować studentom specjalizację w tym kierunku. W niniejszym artykule przedstawiono dwa projekty, które przybliżają temat thumaczeń spraw socjalnych. Ponadto omówiony został także rozwój modułów/wzorców tego typu tłumaczeń.

\section{Przełożyła Beata Popławska}

Słowa kluczowe: ustne tłumaczenia spraw socjalnych; pisemne thumaczenia spraw socjalnych; IGA; PACI; traduktologia; wielojęzyczność; instytucjonalizacja.

\section{THE IMPORTANCE OF SOCIAL INTERPRETING AS AN INSTRUMENT OF TOLERANCE IN THE CONTEXT OF CURRENT REFUGEE AND LABOUR MIGRATION}

\section{S u m m a ry}

As a result of social changes in society in Western Europe at the end of the 20th century, it was recognised that a new perspective on interpreting science was needed. For a long time, community interpreting was ignored or considered inferior in comparison to the dominant interpreting mode, namely, conference interpreting.

Intensifying trade contacts and labour migration within the European Union have, in combination with the current influx of refugees, led to a high demand for interpreting services in the 
field of social and legal interpreting. Additionally, there is only a limited number of qualified interpreters available on the market, especially in combinations of less widely-spoken languages. The lack of qualified community interpreters and translators has direct consequences for delays in the functioning of certain government bodies and social services. The same applies to the quality of healthcare provided and to the social climate. Increasing the scale of interpreting and translation assignments, changing the professional profile of the interpreter and raising the demand for the provision of language services in specific language combinations are clear signals for small philological departments to offer their students the opportunity to specialise in this area. For this reason, two projects are presented in this article, both of which aim at promoting know-how in the field of social interpreters and at developing modules in social interpreting and translation.

Key words: community interpreting; community translation; IGA; PACI; interpreting studies; multilingualism; institutionalisation. 